\title{
On the crossing number of join of the wheel on six vertices with the discrete graph
}

\section{ŠTEFAN BEREŽNÝ and Michal STAŠ}

\begin{abstract}
.
The main aim of the paper is to give the crossing number of join product $W_{5}+D_{n}$ for the wheel $W_{5}$ on six vertices, and $D_{n}$ consisting of $n$ isolated vertices. In the proofs, it will be extend the idea of the minimum numbers of crossings between two different subgraphs from the family of subgraphs which do not cross the edges of the graph $W_{5}$ onto the family of subgraphs that cross the edges of $W_{5}$ at least twice. Further, we give a conjecture that the crossing number of $W_{m}+D_{n}$ is equal to $Z(m+1) Z(n)+(Z(m)-1)\left\lfloor\frac{n}{2}\right\rfloor+n$ for $m$ at least three, and where the Zarankiewicz's number $Z(n)=\left\lfloor\frac{n}{2}\right\rfloor\left\lfloor\frac{n-1}{2}\right\rfloor$ is defined for $n \geq 1$. Recently, our conjecture was proved for the graphs $W_{m}+D_{n}$, for any $n=3,4,5$, by Klešč et al., and also for $W_{3}+D_{n}$ and $W_{4}+D_{n}$ due to the result by Klešč, Schrötter and by Staš, respectively. Clearly, the main result of the paper confirms the validity of this conjecture for the graph $W_{5}+D_{n}$.
\end{abstract}

\section{REFERENCES}

[1] Berežný, Š. and Buša, Jr., J., Algorithm of the Cyclic-Order Graph Program (Implementation and Usage), J. Math. Model. and Geometry, 7 (2019), No. 3, 1-8

[2] Berežny, Š. and Staš, M., Cyclic permutations and crossing numbers of join products of symmetric graph of order six, Carpathian J. Math., 34 (2018), No. 2, 143-155

[3] Berežný, Š. and Staš, M., Cyclic permutations and crossing numbers of join products of two symmetric graphs of order six, Carpathian J. Math., 35 (2019), No. 2, 137-146

[4] Clancy, K., Haythorpe, M. and Newcombe, A., A survey of graphs with known or bounded crossing numbers, arXiv:1901.05155 (2019), Section 4.4.1

[5] Hernández-Vélez, C., Medina, C. and Salazar, G., The optimal drawing of $K_{5, n}$, Electron. J. Combin., 21 (2014), No. 4, \#P4.1, 29 pp.

[6] Garey, M. R. and Johnson, D. S. Crossing number is NP-complete SIAM J. Algebraic. Discrete Methods, 4 (1983), 312-316

[7] Kleitman, D. J., The crossing number of $K_{5, n}$, J. Combinatorial Theory, 9 (1970), 315-323

[8] Klešč, M., The crossing number of join of the special graph on six vertices with path and cycle, Discrete Math., 310 (2010), 1475-1481

[9] Klešč, M., The join of graphs and crossing numbers, Electron. Notes in Discrete Math., 28 (2007), 349-355

[10] Klešč, M., Kravecová, D. and Petrillová, J., The crossing numbers of join of special graphs, Electrical Engineering and Informatics 2: Proceeding of the Faculty of Electrical Engineering and Informatics of the Technical University of Košice, (2011), 522-527

[11] Klešč, M., Petrillová, J. and Valo, M., On the crossing numbers of Cartesian products of wheels and trees, Discuss. Math. Graph Theory, 71 (2017), 339-413

[12] Klešč, M. and Schrötter, Š., The crossing numbers of join of paths and cycles with two graphs of order five, Combinatorial Algorithms, Sprinder, LNCS, 7125 (2012), 160-167

[13] Klešč, M. and Schrötter, Š., The crossing numbers of join products of paths with graphs of order four, Discuss. Math. Graph Theory, 31 (2011), 321-331

Received: 27.02.2020; In revised form: 11.06.2020; Accepted: 18.06.2020

2010 Mathematics Subject Classification. 05C10, 05C38.

Key words and phrases. Graph, drawing, crossing number, join product, cyclic permutation.

Corresponding author: Michal Staš; michal.stas@tuke.sk 
[14] Klešč, M. and Valo, M., Minimum crossings in join of graphs with paths and cycles, Acta Electrotechnica et Informatica, 12 (2012), No. 3, 32-37

[15] Kulli, V. R. and Muddebihal, M. H. Characterization of join graphs with crossing number zero Far East J. Appl. Math., 5 (2001), 87-97

[16] Ma, Z. and Cai, J., The Crossing Number of $W_{5} \times S_{n}$, Acta. Math. Appl. Sinica, 31 (2008), No. 4, 615-623

[17] Mei, H. and Huang, Y., The Crossing Number of $K_{1,5, n}$, Int. J. Math. Combin., 1 (2007), No. 1, 33-44

[18] Staš, M., Cyclic permutations: Crossing numbers of the join products of graphs, Proc. Aplimat 2018: $17^{\text {th }}$ Conference on Applied Mathematics, (2018), 979-987

[19] Staš, M., Determining crossing numbers of graphs of order six using cyclic permutations, Bull. Aust. Math. Soc., 98 (2018), 353-362

[20] Staš, M., On the crossing number of the join of the wheel on five vertices with the discrete graph, Bull. Aust. Math. Soc., 101 (2020), 353-361

[21] Woodall, D. R., Cyclic-order graphs and Zarankiewicz's crossing number conjecture, J. Graph Theory, 17 (1993), 657-671

\author{
DEPARTMENT OF MATHEMATICS AND THEORETICAL INFORMATICS \\ FACULTY OF ELECTRICAL ENGINEERING AND INFORMATICS \\ TECHNICAL UNIVERSITY OF KOŠICE \\ KOŠICE, SLOVAKIA \\ Email address: stefan. berezny@tuke.sk \\ Email address: michal.stasetuke.sk
}

